\title{
Degradation of Ethylene Diaminetetra Acetic Acid With Ferrous Ions Using Fenton's Reagent in Absence of Light
}

\author{
Ajay Kumar Mishra ${ }^{1}$, S Velmurugan ${ }^{2}$, B S Panigrahi ${ }^{3}$, Biplob Paul ${ }^{1}$, S Chitra ${ }^{1}$, S K Khandelwal ${ }^{1}$ \\ ${ }^{1}$ Centralized Waste Management Facility, Bhabha Atomic Research Centre Facilities, Kalpakkam, India \\ ${ }^{2}$ Water Chemistry Division Bhabha Atomic Research Centre Facilities, Kalpakkam, India \\ ${ }^{3}$ Indira Gandhi Center for Atomic Research, Kalpakkam, India \\ Correspondence: Ajay Kumar Mishra, Centralized Waste Management Facility, Bhabha Atomic Research Centre \\ Facilities Kalpakkam, India. E-mail: aju612@gmail.com
}

Received: July 8, 2019 Accepted: July 31, 2019 Online Published: August 12, 2019

doi:10.5539/ijc.v11n2p110 URL: https://doi.org/10.5539/ijc.v11n2p110

\begin{abstract}
Accumulation of deposit corrosion products inside secondary side of steam generator can lead to serious issue for pressurized water reactor in operation.One way to avoid accumulation of these deposits is to perform chemical cleaning which removes certain amount of deposits but this kind of operation generates high amount of liquid waste which contains process chemicals and metal ions in complex state. Oxidation of complexes will render radioactive ions in free state enabling us for further treatment to innocuous level and condition. In waste treatment there are various treatment technologies (advance oxidation process, ozone, hydrogen peroxide, electrochemical oxidation, supercritical water oxidation, electro flocculation etc to remove the accumulated deposit.).In decontamination process removal of the deposits was carried out using EDTA. which complexes the metal ions but it generates secondary waste with EDTA. We have made an attempt to degrade ethylene diaminetetra acetic acid (with ferrousions) using Fenton's reagent in absence of light. This will free the radioactive ion for further treatment. We have studied different volume of hydrogen peroxide $\left(\mathrm{H}_{2} \mathrm{O}_{2}\right)$ and different concentration of ethylene diamine tetra acetic acid (EDTA). Study was also done to find the effect of $\mathrm{pH}$ and temp on the degradation of EDTA. In the range of concentration of ethylene diamine tetra acetic acid 400ppm to $22500 \mathrm{ppm} \%$ degradation was found to change from 57 to $98 \%$ in $180 \mathrm{~min}$. The $\mathrm{pH}$ was found to change from 4.0 to 8.2 . The temperature was found to change from $298 \mathrm{~K}$ to $328 \mathrm{~K}$. The rate constant of the degradation reaction was found to be in the range $10^{-4}$ to $10^{-3}$ in temperature range $298 \mathrm{~K}$ to $328 \mathrm{~K}$. Activation energy for degradation reaction was found to be $33-88 \mathrm{KJ} / \mathrm{mol}$.
\end{abstract}

Keywords: Fenton's reagent, degradation, EDTA

\section{Introduction}

During the operation of Pressurized Water Reactor, corrosion product and impurities are transported into nuclear steam generator by feed water. To mitigate the accumulation of these deposits, chemical cleaning process was carried out. This process uses a mixture of dilute amino carboxylic/carboxylicacids and reducing/oxidizing agents to remove the oxide film and the activity deposited on the out-of-core surfaces of nuclear power reactors. EDTA is normally used as the main chelating agent in the chemical formulation employed [Rufus A L, 2004]. which generates high amount of liquid waste. Depending upon nature of waste to be treated (composition, concentration) specific waste treatment technology has to be selected and optimized. The presence of EDTA used as decontaminating agent in chemical cleaning process waste can cause complexion of cations resulting in interference with their removal during chemical treatment process, ( For example chemical precipitation, ion exchange process etc) [Chitra etal, 1991]. Hence the first step involve oxidation of EDTA complaxing radioactive ions, for which methods like chemical, photochemical oxidation are opted. Literature indicates uses of complexes like EDTA, NTA PICLONIC ACID for this purpose. In essence, it is imperative to free the radioactive ions from the complexes to enable further treatment (chemical precipitation, ion exchange, membrane process etc.) depending upon activity level and immobilized the radioactive ion containing the materials (sludge etc). in suitable mattress( Cement, bitumen glass etc) to avoid leaching to environment. In this paper we deal with oxidation of EDTA used as complaxing agent in view of its versatility, easy availability well known chemistry etc. Also ethylenediamine tetraacetic acid is not easily biodegradable, scarcely degradable by chlorine and hardly retained by activated carbon filters [Hinck ML, 1997; Brauch HJ etal, 1987]. In the present study, degradation of EDTA by using $\mathrm{H}_{2} \mathrm{O}_{2}$ alone at alkaline $\mathrm{pH}$ in absence of light has been reported. After oxidation resulting effluent almost free of activity can be fixed in cement [Rosikoa K etal, 1998]. 


\section{Material and Methods}

\subsection{Chemicals and reagents}

EDTA (AR grade), hydrogen peroxide (30\% w/v), ammonia (10\% w/v), $\mathrm{FeSO}_{4} .7 \mathrm{H}_{2} \mathrm{O}, \mathrm{MgSO}_{4}$ and Eriochrome black-T etc procured from E-Merck were used for the experiments.

$\mathrm{pH}$ meter of make Elico was used to study the $\mathrm{pH}$ during course of reaction. Standard solution of $\mathrm{pH} 4.6,7.2$ and 10.5 were used for calibrating the $\mathrm{pH}$ meter. Spectrophotometer of make (chemeto-2000) was used for the analysis.

Undegraded ethylenediamine tetra acetic acid was estimated titrimetrically using $\mathrm{MgSO}_{4}$ with Eriochrome black-T as an indicator. The results of the analysis were cross checked spectrophotometrically with Ferric EDTA Method at $\lambda$ max 358 to $305 \mathrm{~nm}$ [Aphaetal pp600].

\subsection{Experimental}

A stock solution of ethylenediamine tetraacetic acid of strength $24500 \mathrm{ppm}$ was prepared in ammonical medium. Same solution was used for preparing ethylenediamine tetraacetic acid solution of different strengths viz $400 \mathrm{ppm}, 1600 \mathrm{ppm}$, $4000 \mathrm{ppm}$ and 22500ppm. The iron EDTA complex is made by taking $400 \mathrm{ppm}$ to 22,500ppm EDTA with one to two gram of iron in form of $\mathrm{FeSO}_{4}$.

Two to nine $\mathrm{ml}$ of ammonia (10\% w/v), was added for dissolving EDTA. 30 to $45 \mathrm{ml} \mathrm{H}_{2} \mathrm{O}_{2}(30 \% \mathrm{w} / \mathrm{v})$ was added and made up 1 litre.Undegraded EDTA was estimated at interval of 0 to 24 hour using spectrophotometer.

One litre of $400 \mathrm{ppm}$ was taken in beaker which was wrapped with black paper to avoid intrusion of light. $25 \mathrm{ml}$ of hydrogen peroxide $(30 \% \mathrm{w} / \mathrm{v})$ and $1 \mathrm{gm}$ of $\mathrm{FeSO}_{4}$ were added and mixed thoroughly. Temperature was maintained by thermostating the beaker. $\mathrm{pH}$ was monitored as function of time, Sampling $(10 \mathrm{ml})$ was done every $30 \mathrm{~min}$ and undegraded ethylenediamine tetraacetic acid was carried out. Experiments were repeated without controlling the temperature allowing the temperature to change and $\mathrm{pH}$ was monitored at regular interval.

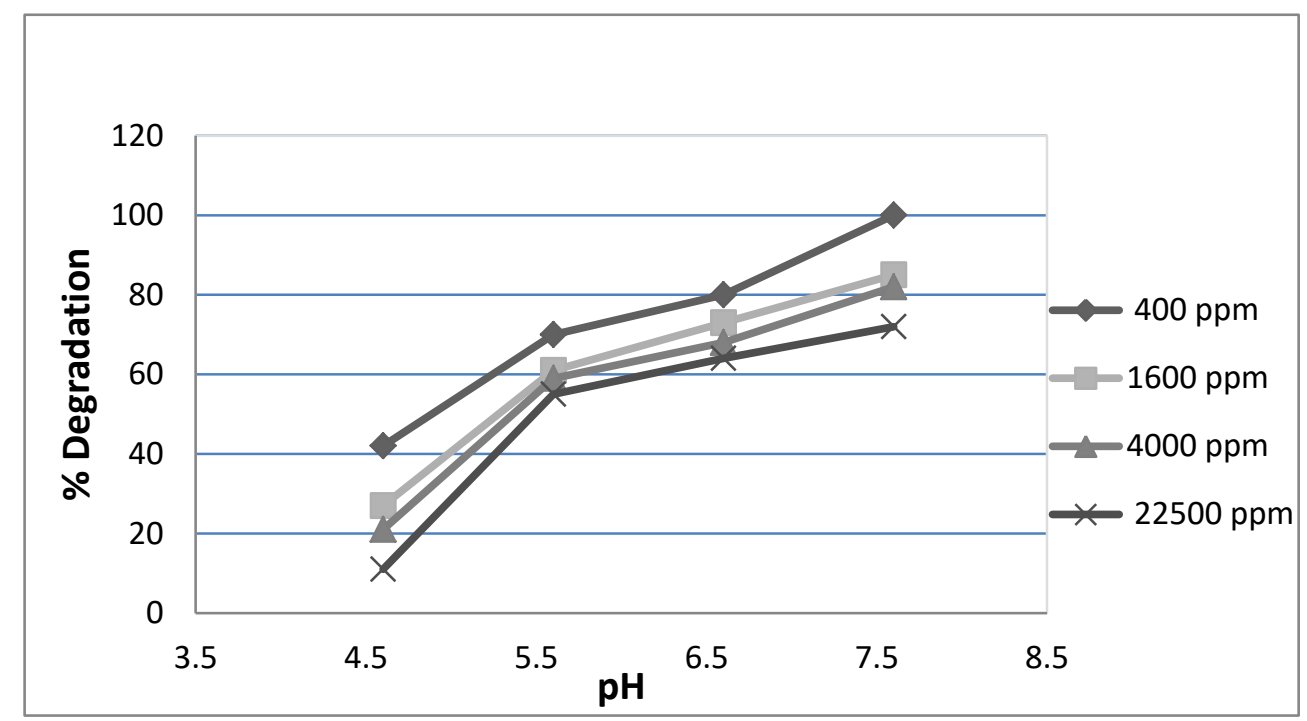

Figure 1. Shows the $\%$ degradation of EDTA of different strength as function of $\mathrm{pH}$ of the initial solution at $35^{\circ} \mathrm{C}$ 


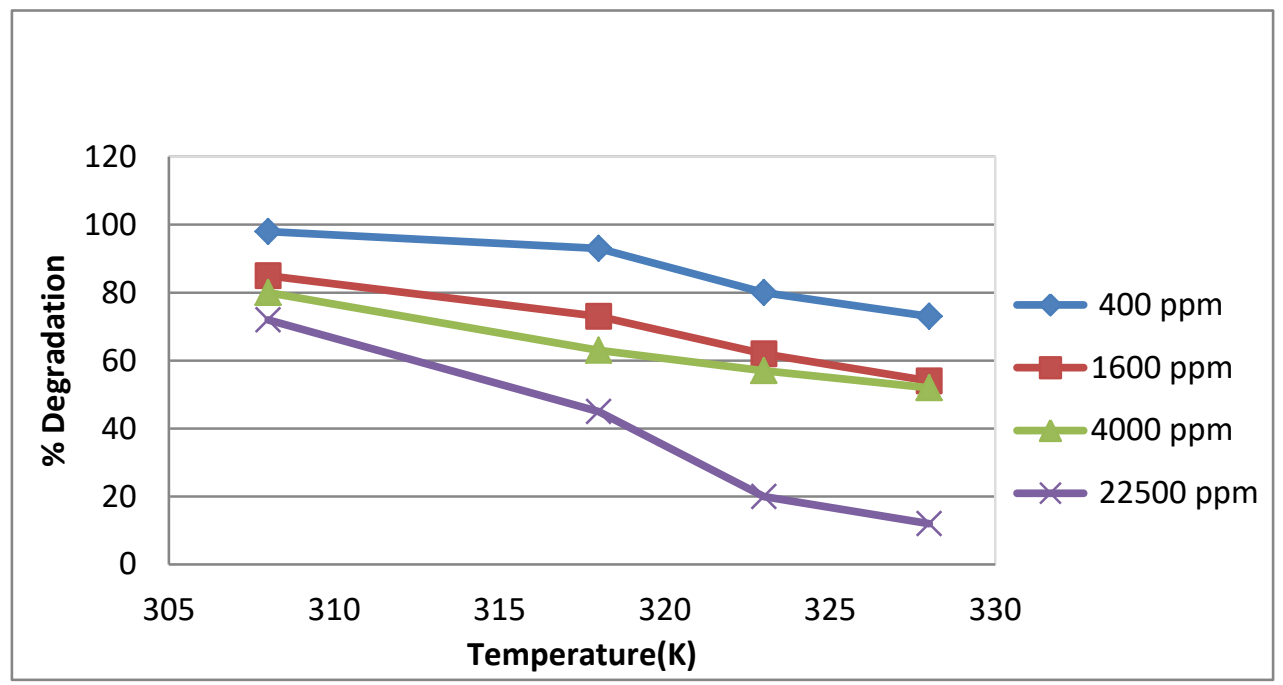

Figure 2. Shows the \% degradation of EDTA of different strengthas function of temperature in 180 minutes duration

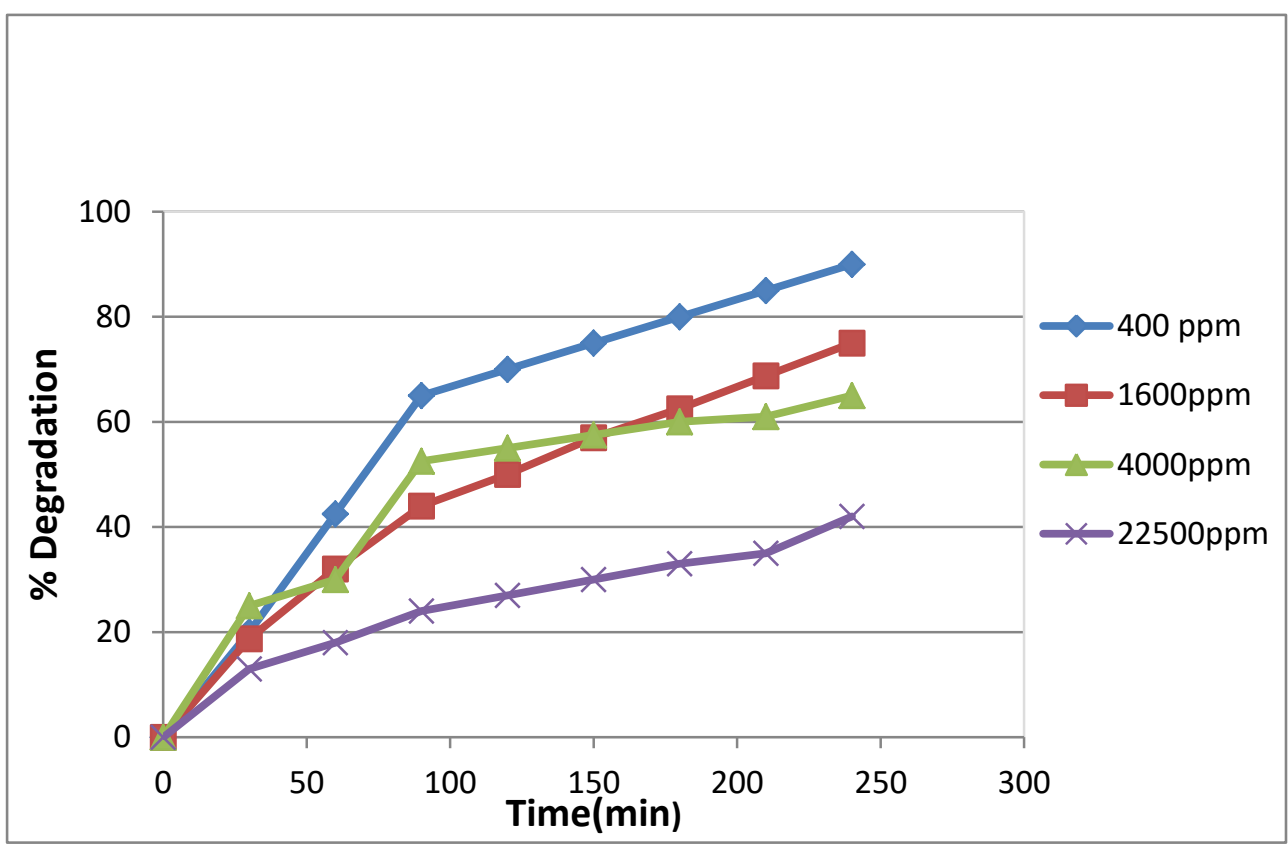

Figure 3. Shows \% degradation of EDTA of different strength at function of different time 


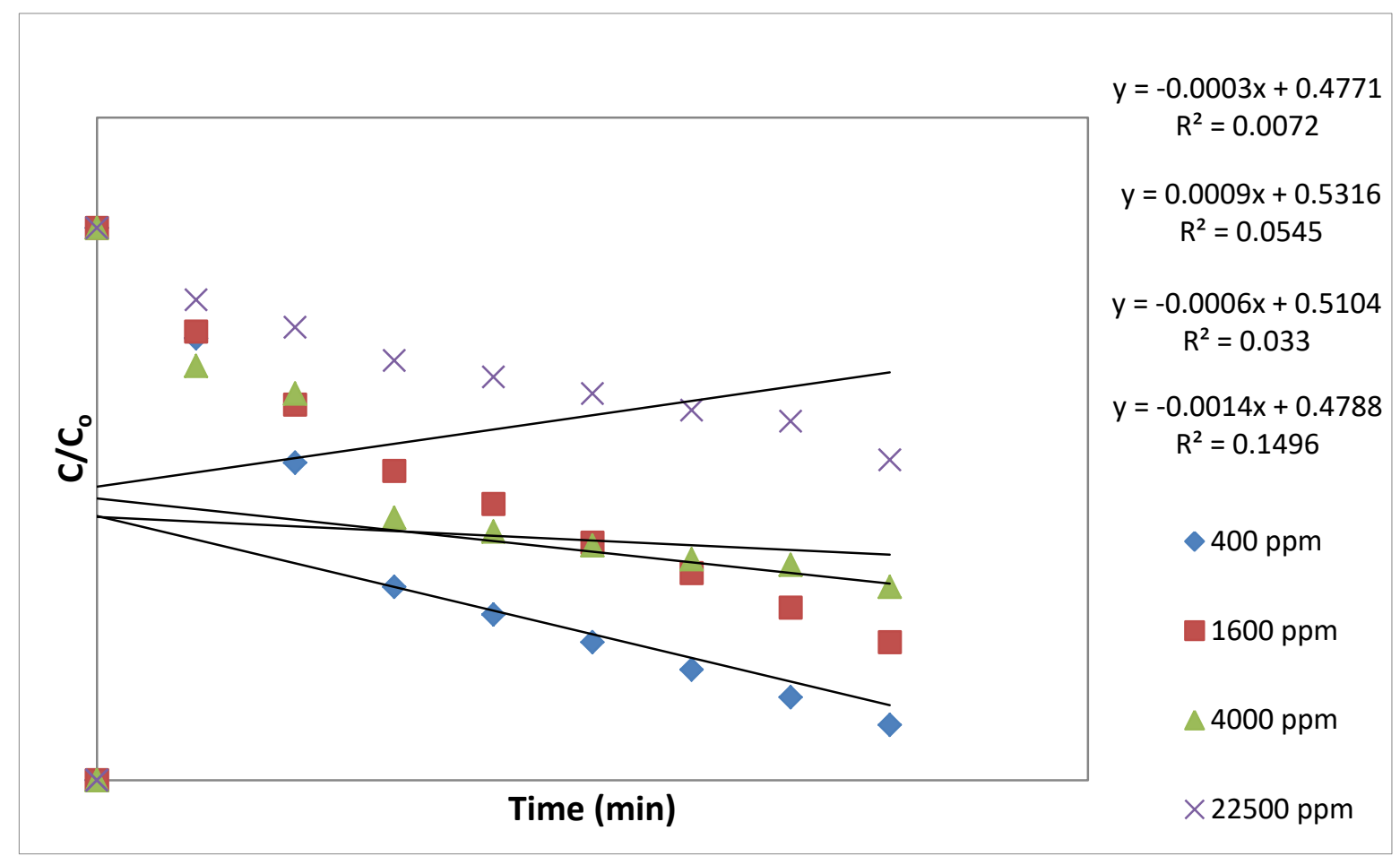

Figure 4. Shows variation of $\left(C / C_{0}\right)$ of EDTA of different strength as function of reaction time. Where $C$ and $\mathrm{C}_{0}$ are the strength of EDTA at various instants and initial strengths respectively

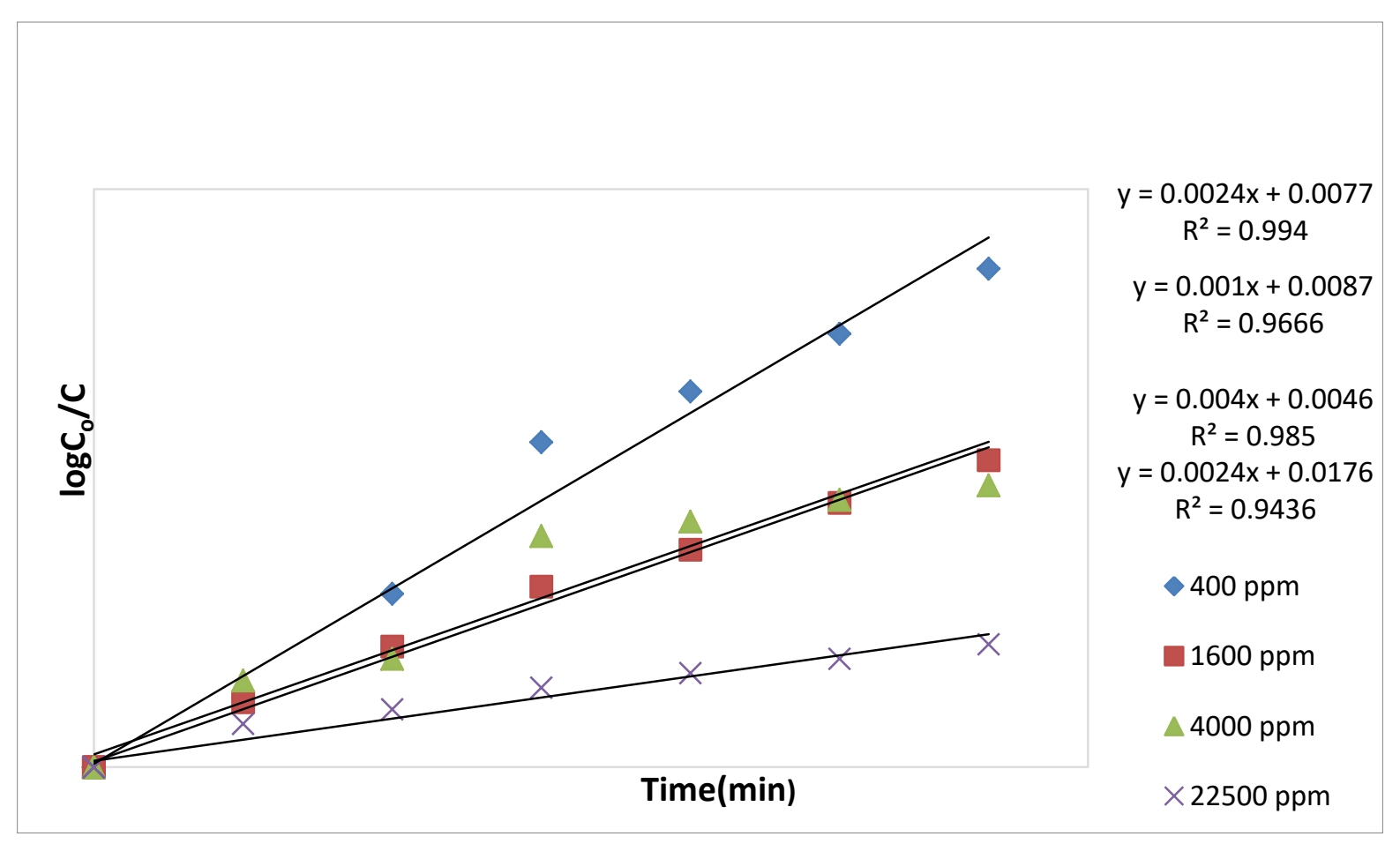

Figure 5. Study of kinetics of degradation of EDTA at various strength

Rate constants of the degradation reactions were computed and log $\mathrm{K}$ was plotted against 1/T. Fig $6 \mathrm{a}$ to $6 \mathrm{~d}$ shows variation of $\log \mathrm{K}$ ( rate constant) as function of 1/T for EDTA solution of different strength.

6a-6d shows the rate constants for all the concentrations of EDTA at $298 \mathrm{~K}$ and $\mathrm{pH}=6.8$. 
Fig. 6a Variation of $\log K$ as function of 1/T with the strength of EDTA 400 ppm at $\mathrm{pH}=6.8$

$$
\text { 1/T } \text { min }^{-1}
$$

$$
\begin{gathered}
y=1260.6 x-7.6171 \\
R^{2}=0.0502
\end{gathered}
$$

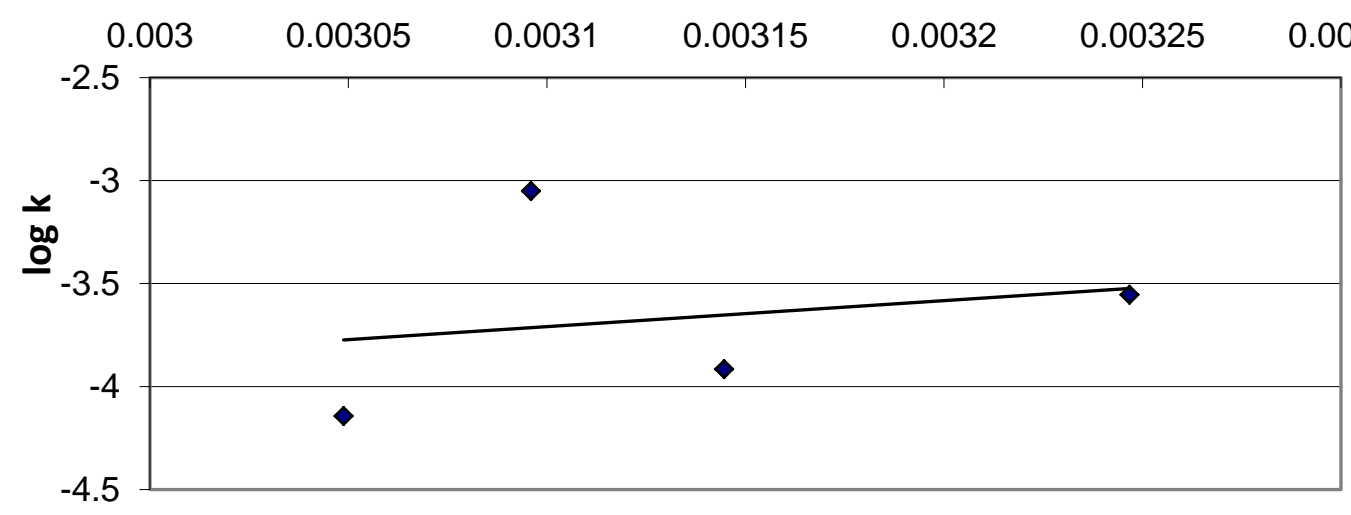

Fig. $6 \mathrm{~b}$ Variation of logk as function of 1/T with EDTA strength of

$$
\begin{array}{cc}
\text { 1600ppm at } \mathrm{pH}=6.8 & \mathrm{y}=1684.7 \mathrm{x}-9.2673 \\
\text { 1/T } \mathrm{min}^{-1} & \mathrm{R}^{2}=0.9183
\end{array}
$$

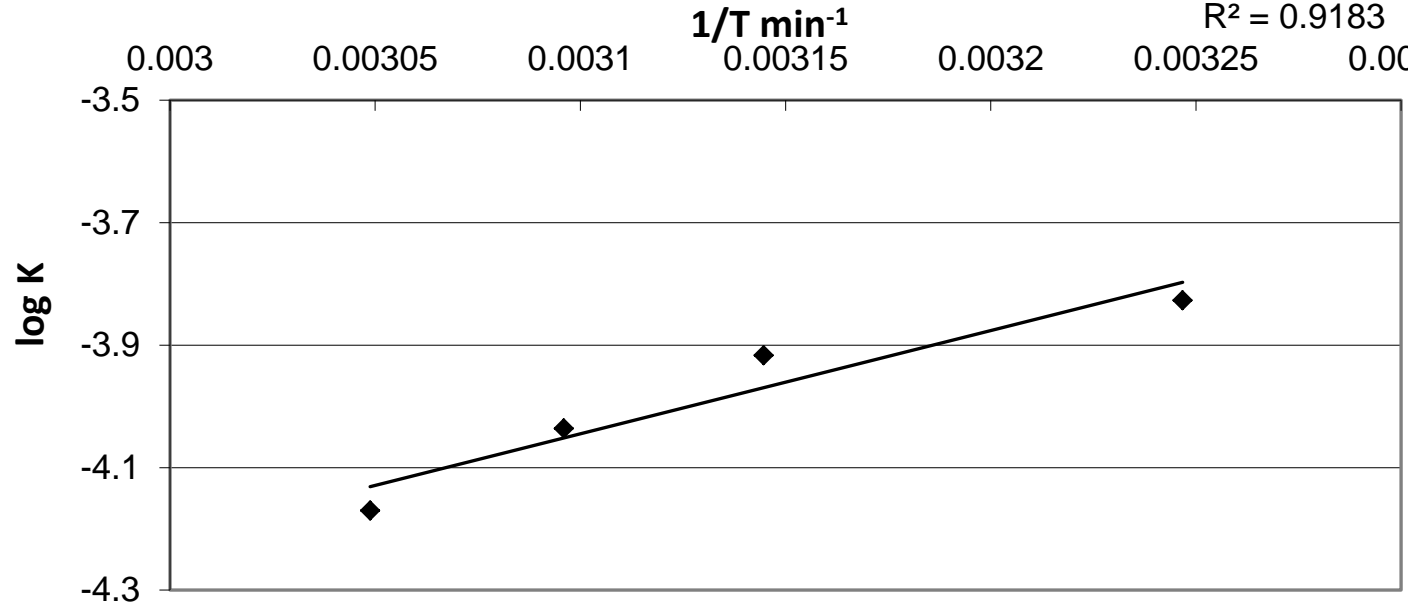


Fig. 6c Variation of $\log K$ as function of $1 / T$ with EDTA strength of $4000 \mathrm{ppm}$ at $\mathrm{pH}=6.8$

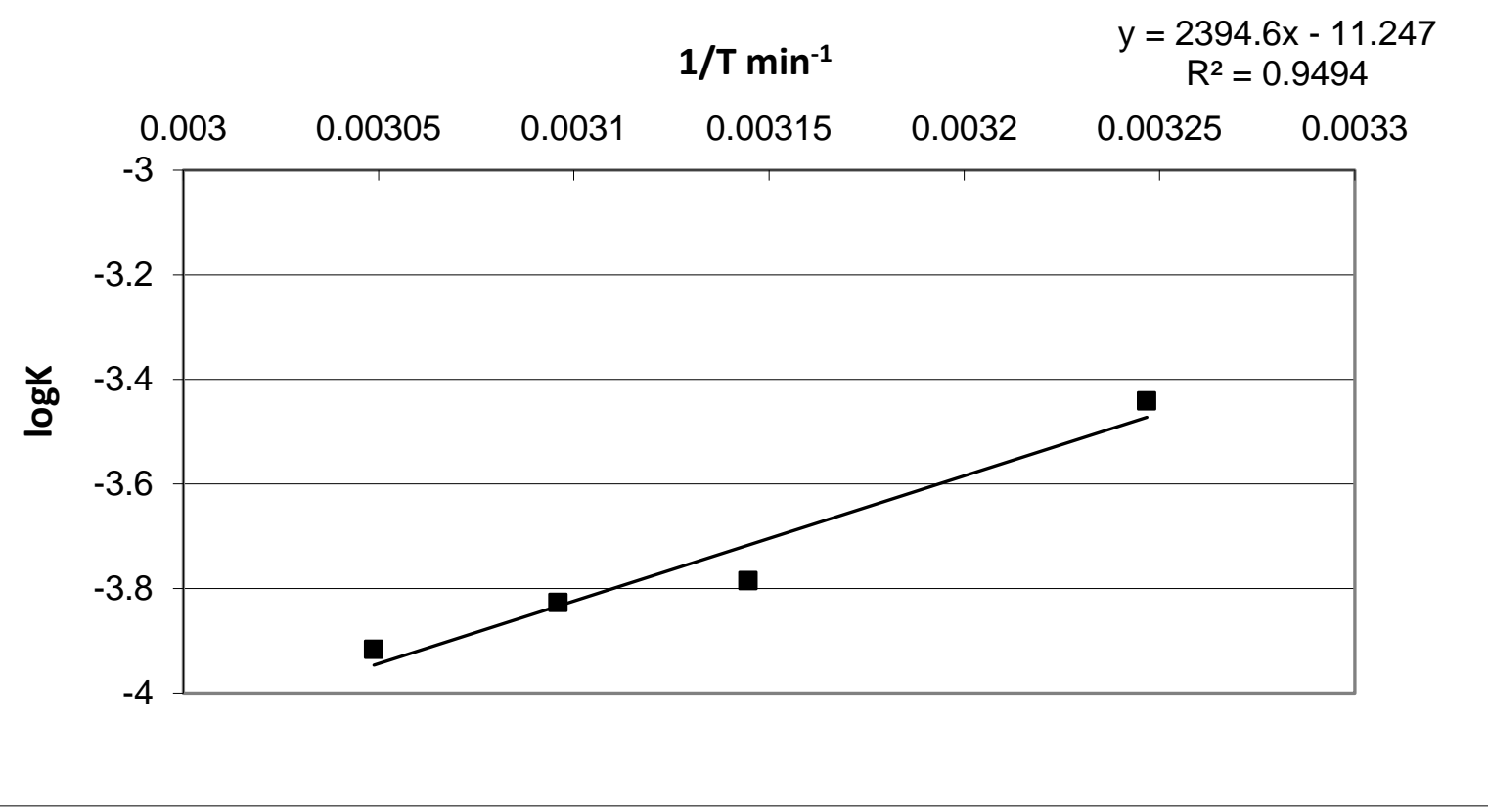

Fig. $6 \mathrm{~d}$ variation of $\log \mathrm{K}$ as function of $1 / \mathrm{T}$ with EDTA strength of $22500 \mathrm{ppm}$ at $\mathrm{pH}-6.8$

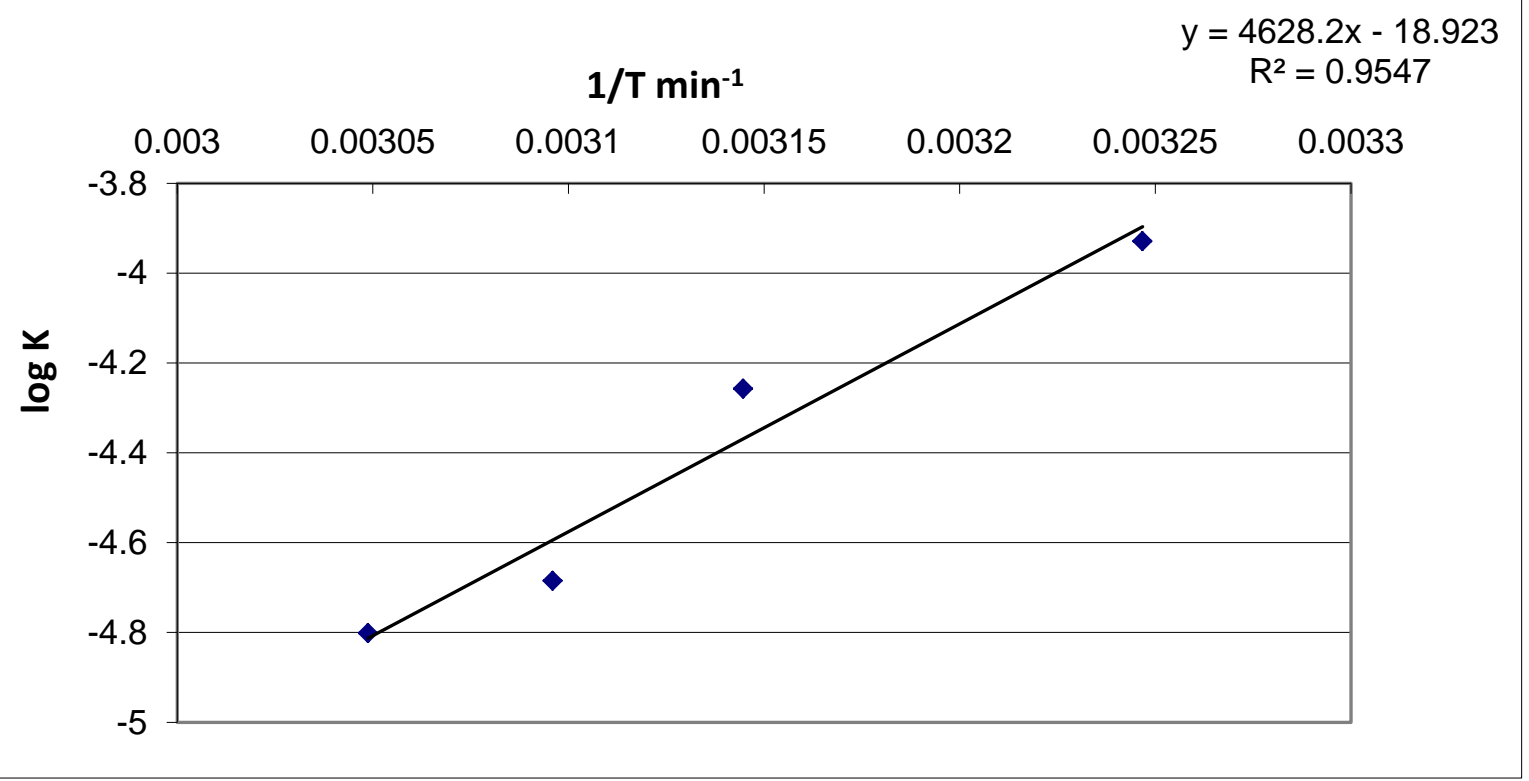

Figure 6. Shows the plot of $\log \mathrm{K}$ as function of $1 / \mathrm{T}$ 
Table 1. Activation energy of the degradation reaction was carried out at various strengths of EDTA using Arrhenius equation and table shows the variation of activation energy as function of strength of EDTA (Activation Energy for Degradation of different strength of EDTA in ppm)

Table 1. Activation Energy for Degradation of different strength of EDTA in ppm

\begin{tabular}{l|l|c}
\hline SN & Strength $(\mathrm{ppm})$ & Activation energy $(\mathrm{KJ} / \mathrm{mol})$ \\
\hline 1 & 400 & 32.25 \\
\hline 2 & 1600 & 40.21 \\
\hline 3 & 4000 & 45.85 \\
\hline 4 & 22500 & 88.616 \\
\hline
\end{tabular}

Table 2. which is the variation of $\mathrm{pH}$ with \% degradation of EDTA pH values of EDTA becomes alkaline with more degradation because of the production of ammonia as the degradation process progresses

Table 2. Effect of $\mathrm{pH}$ at $35^{\circ} \mathrm{C}$ time $180 \mathrm{~min}$

\begin{tabular}{l|l|l|l|l}
\hline $\mathrm{pH}$ & $\begin{array}{l}\% \\
\text { degradation } \\
\text { of 400 ppm }\end{array}$ & $\begin{array}{l}\% \\
\text { degradation } \\
\text { of 1600 } \\
\mathrm{ppm}\end{array}$ & $\begin{array}{l}\% \text { degradation } \\
\text { of 4000 } \\
\mathrm{ppm}\end{array}$ & $\begin{array}{l}\% \\
\text { degradation } \\
\text { of 22500 } \\
\mathrm{ppm}\end{array}$ \\
\hline 4.6 & 42 & 27 & 21 & 11 \\
\hline 5.6 & 70 & 61 & 59 & 55 \\
\hline 6.6 & 80 & 73 & 68 & 64 \\
\hline 7.6 & 100 & 85 & 82 & 72 \\
\hline
\end{tabular}

Table 3. shows that the temp rise with time during degradation process under uncontrolled condition. Moreover the increase in temperature is more during degradation EDTA of lower concentration.

Table 3. Effect of uncontrolled Temperature $180 \mathrm{~min}$

\begin{tabular}{l|l|l|l|l}
\hline \multirow{2}{*}{$\begin{array}{l}\text { Time } \\
\text { min }\end{array}$} & \multicolumn{5}{|l}{ Temperature of EDTA sol of Different Concentration } \\
\cline { 2 - 5 } & $\begin{array}{l}\% \text { degradation of } 400 \\
\text { ppm }\end{array}$ & $\begin{array}{l}\text { \%degradation of } 1600 \\
\text { ppm }\end{array}$ & $\begin{array}{l}\% \text { degradation of } \\
4000 \mathrm{ppm}\end{array}$ & $\begin{array}{l}\% \text { degradation of } \\
22500 \mathrm{ppm}\end{array}$ \\
\hline 00 & 28 & 28 & 28 & 28 \\
\hline 30 & 39 & 36 & 35 & 30 \\
\hline 60 & 42 & 40 & 38 & 39 \\
\hline 90 & 44 & 42 & 40 & 40 \\
\hline 120 & 46 & 44 & 42 & 41 \\
\hline 150 & 48 & 46 & 44 & 42 \\
\hline 180 & 50 & 48 & 46 & 44 \\
\hline
\end{tabular}

\section{Result and Discussion}

The oxidation of EDTA was carried out by the hydroxyl radicals generated from $\mathrm{H}_{2} \mathrm{O}_{2}$ [Gilbert $\mathrm{E}$ etal, 1990;SoresenM,1995; Tucker MD, 1999; KrapfenbauerK,1999;SuY,1998].The generation of hydroxyl radical depends upon $\mathrm{pH}$ value. Formation of Hydroxyl radical by Using Fenton process occurs according to the following equation.

$\mathrm{Fe}^{2+}+\mathrm{H}_{2} \mathrm{O}_{2} \rightarrow \mathrm{Fe}^{3+}+\mathrm{OH}^{-}+{ }^{\circ} \mathrm{OH}$

$\mathrm{Fe}^{3+}+{ }^{\circ} \mathrm{OH} \rightarrow \mathrm{Fe}^{2+}+\mathrm{OH}$

$$
\begin{aligned}
& \mathrm{Fe}^{3+}+\mathrm{H}_{2} \mathrm{O}_{2} \rightarrow \mathrm{Fe}^{2+}+\mathrm{HO}_{2}^{\cdot}+\mathrm{H}^{+} \\
& \mathrm{Fe}^{3+}+\mathrm{HO}_{2} \rightarrow \mathrm{Fe}^{2+}+\mathrm{HO}_{2}^{\cdot}+\mathrm{H}^{+} \\
& \mathrm{Fe}^{2+}+\mathrm{H}_{2} \mathrm{O}_{2} \rightarrow \mathrm{Fe}^{3+}+\mathrm{OH}^{-}+{ }^{\bullet} \mathrm{OH} \\
& \mathrm{Fe}^{2+}+{ }^{\circ} \mathrm{OH} \rightarrow(\mathrm{Fe}-\mathrm{OH})^{2+}
\end{aligned}
$$


Since hydroxyl radical react with $\mathrm{H}_{2} \mathrm{O}_{2}$ the later contribute to hydroxyl scavengers [Ghalyetal, 2001]. There was $\mathrm{pH}$ changing to alkaline condition in which case formation of acidic intermediate is possible. This is in agreement with the result obtain by other investigator regarding the mechanism of chemical degradation of EDTA [VirtapohjaJ,1998].Effectively EDTA gets degraded into $\mathrm{CO}_{2}$ and $\mathrm{NH}_{3}$ by the Hydroxyl radical generated as in the above equation.

First our $\mathrm{Fe}^{+2} / \mathrm{H}_{2} \mathrm{O}_{2}$ produces hydroxyl radical and recycling the ferrous catalyst increases $\mathrm{Fe}(\mathrm{II})$ ions by reduction of $\mathrm{Fe}(\mathrm{III})$ to $\mathrm{Fe}(\mathrm{II})$. As a result, concentration $\mathrm{Fe}^{+2}$ increases and therefore gross reaction is accelerated and hence increase in rate of degradation to $80 \%$.The oxidizing power of hydroxyl radical is more than hydro peroxide radical.

From Figure 1 we find that in the $\mathrm{pH}$ value change 4.6 to 7.6 the $\%$ degradation was found to increase at all initial strength of EDTA ( $400 \mathrm{ppm}$ to $22500 \mathrm{ppm}$ ) indicating that the alkaline conditions favour the oxidation reactions.

From Figure 2 (which shows the \% degradation of EDTA as function of temperature) under controlled temperature condition in period of $180 \mathrm{~min}$ time shows that degradation is more at lower temperatures indicating exothermicity of the reaction.

From Table 1 we find that Activation energy in $\mathrm{KJ} / \mathrm{mol}$ ranges between 32.25 to 88.62 in the concentration range of 400 to $22500 \mathrm{ppm}$.

From table 2 we find that $\%$ degradation decreases with conc with $\mathrm{pH}$ ranging 4.6 to 7.6 at $35^{\circ} \mathrm{C}$ in 180 min duration.

From Table 3 which indicates the increase in temperature as the degradation progresses shows that the temperature increases with more oxidation giving credence to the exothermic nature of the reaction.

Also the Degradation was found to be more with lesser initial concentration of EDTA. The availability of more hydroxyl radicals with lesser initial strength of EDTA aids in the more degradability of EDTA of lower strength.

Figure 4 Which indicates variation of $C / C_{0}\left(C\right.$ strength at various instance and $C_{o}$ initial conc.) shows that with more initial conc. degradation is less.

From figure 5 we observe that the plot of $\log \left(\mathrm{C} / \mathrm{C}_{\mathrm{o}}\right)$ as a function of time are straight lines passing through origin indicating first order kinetics of the reaction.

Rate constant at various temperature is carried out using first order rate expression

$$
k=\frac{2.303}{t} \log \left(\frac{C o}{C}\right)
$$

Where $\mathrm{C}_{\mathrm{o}}$ - Initial concentration of ethylenediamine tetraacetic acid

C-remaining concentration of ethylenediamine tetraacetic acid

$\mathrm{k}$ - Rate constant for different concentration at various temperature.

Rate constant was found to change from $0.0003622 \mathrm{sec}^{-1} 1$ to $.00001212 \mathrm{sec}^{-1}$ in time interval 0 sec to $10800 \mathrm{sec}$ and temperature change was $35^{\circ} \mathrm{C}$ to $55^{\circ} \mathrm{C}$ for $400 \mathrm{ppm}$ concentration.

Rate constant was found to change from $0.0001756 \mathrm{sec}-1$ to $.0000729 \mathrm{sec}^{-1}$ in time interval $0 \mathrm{sec}$ to $10800 \mathrm{sec}$ and temperature change was $35^{\circ} \mathrm{C}$ to $55^{\circ} \mathrm{C}$ for $1600 \mathrm{ppm}$ concentration.

Rate constant was found to change from $0.000149 \mathrm{sec}^{-1}$ to $.0000675 \mathrm{sec}^{-1}$ in time intervals 0 sec to $10800 \mathrm{sec}$ and temperature change was $35^{\circ} \mathrm{C}$ to $55^{\circ} \mathrm{C}$ for $4000 \mathrm{ppm}$ concentration.

Rate constant was found to change from $0.0001178 \mathrm{sec}^{-1}$ to $.0001183 \mathrm{sec}^{-1}$ in time intervals $0 \mathrm{sec}$ to $10800 \mathrm{sec}$ and temperature change was $35^{\circ} \mathrm{C}$ to $55^{\circ} \mathrm{C}$ for $22500 \mathrm{ppm}$ concentration.

Rate constant was found to decrease with increase in the temperature confirming further the exothermicity of reaction.

Activation energy was calculated by plotting $\log \mathrm{K}$ Vs $1 / \mathrm{T}$ using equation

$$
K=A e^{-\frac{E a}{R T}}
$$

where $R$ - Gas constantS

$E a-$ Activation energy

$A$ - Arhinious constant

The activation energy for the $\%$ degradation reaction was carried out by plot $\log K v s 1 / \mathrm{T}$. From the negative(-ve) slope of line the activation energy was calculated, which was found to be $24.18 \mathrm{KJ} / \mathrm{mole}$ to $88 \mathrm{KJ} / \mathrm{mole}$ in the concentration 
range of 400-22500 ppm of EDTA which is in conformity with result of Ramunas $\mathrm{J}$ etal who have reported the activation energy $119.66 \mathrm{KJ} / \mathrm{mole}$ for the EDTA oxidation reactions[Ramunas J etal, 2011].

\section{Conclusion}

Degradation of EDTA using Fenton reagent in absent of light is successfully completed. Under optimized condition, the maximum degradation was accomplished leading to $57 \%$ to $98 \%$ degradation in concentration range of EDTA $22500 \mathrm{ppm}$ to $400 \mathrm{ppm}$. Also the reaction was found to be exothermic with activation energy of $32.25 \mathrm{KJ} / \mathrm{mole}$ to 88 $\mathrm{KJ} / \mathrm{mol}$. in the concentration range of 400 to $22500 \mathrm{ppm}$.

\section{Acknowledgement}

Author expressed that thanks to Smt. Shivkamy, Shri. AG Shanugmani for providing the facility and infrastructure. Author also express sincere thanks to Shri.Rufas and Shri.Akhilesh Joshi.

\section{References}

APHA. Standard methods for the examination of water and waste water. New York. 600.

Brauch, H. J., \& Schullerer, S. V. (1987). Vom Wasser, 69, 155-164.

Chitra, S., Sandhya, C., Sasidhar, P., Lal, K. B., \& Amalraj, R. V. (1991). Ind. J. Env. Pro, 11(9), 689-692.

Ghaly, M. Y., Hartel, G., Mayer, R., \& Haseneder, R. (2001). Waste Management, 21, 41-47. https://doi.org/10.1016/S0956-053X(00)00070-2

Gilbert, E., \& Hoffmann-Glewe, S. (1990). Water, 24, 39-44. https://doi.org/10.1016/0043-1354(90)90062-B

Hinck, M.L., Ferguson, J., \& Puhaakka, J. (1997). Wat. Sci. Tech, 35(2-3), 25-31. https://doi.org/10.2166/wst.1997.0474

Huang, C. P., Cheng, D., \& Zhong, H. T. (1993). Waste Management, 13, 361-377. https://doi.org/10.1016/0956-053X(93)90070-D

Jaakko, R., \& Mika, S. (2001). Journal of Cleaner Production, 9, 191-195. https://doi.org/10.1016/S0959-6526(00)00049-4

Kagaya, S., Bitoh, Y., \& Hasegawa, K. (1997). Chem. Lett, 155-157. https://doi.org/10.1246/cl.1997.155

Krapfenbauer, K., \& Getoff, N. (1999). Rad. Phys. Chem, 55, 385-393. https://doi.org/10.1016/S0969-806X(99)00205-4

Rosikova, K., John, J., Danacikovas-Popelova, E., Sebesta, F., \& Hooper, E. W. (1998). In Proceedings of $4^{\text {th }}$ institute for International Cooperative Environmental Research, Florida State University ,Tallahassee, FL., 379-385.

Schulerer, S., \& Brauch, H. J. (1989). Vom. Wasser, 72, 2329.

Sorensen, M. F., \& Rimmel, F. H. Z. (1995). Naturforsh, 50b, 1845-1853. https://doi.org/10.1515/znb-1995-1211

Su, Y., Wang, Y., Daschbach, J. L., Fryberger, T. B., Henderson, M. A., Janata, J., \& Peden, C. H. F. (1998). J. Adv. Oxid. Technol, 3, 63-69. https://doi.org/10.1515/jaots-1998-0109

Tucker, M. D., Barton, L. L., Thomson, B. M., \& Aragon, A. (1999). Waste Management, 19, 477-482. https://doi.org/10.1016/S0956-053X(99)00235-4

Virtapohja, J., \& Alen, R. (1998). РарPuи, 81, 305-309. https://doi.org/10.1023/A:1006550806531

Vogel, A. I. (1939). Quantitative inorganic analysqis, 363.

\section{Copyrights}

Copyright for this article is retained by the author(s), with first publication rights granted to the journal.

This is an open-access article distributed under the terms and conditions of the Creative Commons Attribution license (http://creativecommons.org/licenses/by/4.0/). 